Tema: Metalurgia Secundária

\title{
MELHORIA DE QUALIDADE SUPERFICIAL NO AÇO 430 ESTABILIZADO AO NIÓBIO ATRAVÉS DO CONTROLE DE TEOR DE ALUMÍNIO*
}

\section{Resumo}

\author{
Márcio Nascimento Cunha ${ }^{1}$ \\ Daniel Luiz Coimbra ${ }^{1}$ \\ Maurício Ferreira Coelho ${ }^{2}$ \\ Valdeci Paula Alvarenga ${ }^{2}$ \\ José Edson de Assis Morais ${ }^{3}$ \\ Leonardo Magalhães Silvestre
}

A presença de inclusões não metálicas em aços inoxidáveis é uma das possíveis fontes de defeitos superficiais, especialmente em produtos laminados a frio. Uma das alternativas para evitar as inclusões de óxido de alumínio em aços inoxidáveis é o rígido controle dos níveis de alumínio presentes nas matérias primas adicionadas ao aço. O presente trabalho tem como objetivo apresentar melhorias de qualidade superficial obtidas no aço ferrítico 430 estabilizado ao nióbio $(0,20 \% \mathrm{Nb}$ a $0,40 \% \mathrm{Nb})$ produzido pela Aperam através do uso de ferro-nióbio contendo menores teores de alumínio em relação ao produto padrão, desenvolvido especialmente para essa aplicação pela empresa fornecedora do material. Através de resultados industriais constatou-se uma evolução da qualidade com a redução no índice de desvios por esfoliação de 29\%, enfatizando não só a importância do controle do teor de alumínio incorporado aos aços inoxidáveis como também um controle rigoroso de processo especialmente em aplicações de alto apelo estético, caso do uso em equipamentos da linha branca.

Palavras-chave: Qualidade superficial; Nióbio; Aço inoxidável.

\section{SURFACE QUALITY IMPROVEMENT IN 430 NIOBIUM STABILIZED STEEL THROUGH THE CONTROL OF ALUMINUN CONTENT}

\section{Abstract}

The presence of non-metallic inclusions in stainless steels is one of the possible sources of surface defects, especially when considering cold rolled products. As available alternative to avoid aluminum oxide inclusions in stainless steels there is a rigid control of the levels of aluminum present in the raw materials used during the steel production. The present work has the objective to present a surface quality improvement achieved in the production of the 430 grade stabilized with niobium $(0,20 \% \mathrm{Nb}$ to $0,40 \% \mathrm{Nb})$ produced by Aperam by the use of a ferro-niobium with lower aluminum contents when compared to the standard product, specially developed by the material supplier. Industrial results have shown an improvement of $29 \%$ in the deviations caused by this type of defect, highlighting the importance not only in the control of the aluminum incorporated in stainless steels but also the importance of having a rigorous process control, especially with regards to very surface finish demanding applications such as household appliances.

Keywords: Surface finish; Niobium; Stainless steels.

1 Engenheiro Metalurgista, Engenheiro metalurgista do produto inox, Aperam South America, Timóteo, MG, Brasil.

2 Engenheiro Metalurgista, Engenheiro metalurgista de processo, Aperam South America, Timóteo, MG, Brasil.

3 Técnico Metalúrgico, Analista de compras, Aperam South America, Timóteo, MG, Brasil.

4 Engenheiro Metalurgista, Gerente de Tecnologia, CBMM, São Paulo, SP, Brasil.

\footnotetext{
* Contribuição técnica ao 45 Seminário de Aciaria - Internacional, 25 a 28 de maio de 2014,
} 


\section{INTRODUÇÃO}

O nível de exigência quanto à limpeza dos aços tem crescido à medida que cresce a demanda por produtos que apresentem não só melhores propriedades mecânicas como também melhor acabamento superficial.

Em aços inoxidáveis, especialmente em aplicações de grande apelo estético, caso dos equipamentos de linha branca, a busca por melhoria na qualidade superficial é uma constante.

Atualmente, dentre os aços inoxidáveis, os aços da família ferrítica vem ganhando espaço no uso em eletrodomésticos tais como revestimento de geladeiras, mesas de fogões, pias e cestos de máquinas de lavar, por apresentarem suficiente resistência à corrosão e bom acabamento superficial a um menor custo, já que usualmente não contém níquel em sua composição.

Dentre os aços da família ferrítica, o aço AISI 430 é aquele que possui maior volume de aplicações. Sua versão estabilizada ao nióbio, o aço $430 \mathrm{E}(0,20$ a $0,40 \% \mathrm{Nb})$, foi desenvolvido pela Aperam especialmente para atender a aplicações em linha branca que exigem maior complexidade quanto à estampabilidade, maior exigência quanto a acabamento superficial e também resistência à sensitização em regiões soldadas.

Para aplicações como essa, onde o acabamento superficial é uma das propriedades finais mais importantes do produto, a presença de inclusões não metálicas da ordem de 10 micrometros já é considerada influencia importante no acabamento superficial [1].

Dentre os principais defeitos causados pela presença de inclusões em aços inoxidáveis está a esfoliação. Em geral ela é causada pela presença de inclusões originadas na Aciaria e que estejam próximas à superfície da placa, a menos de 15 $\mathrm{mm}$ da superfície. Esse defeito pode ter origens distintas, tais como aluminatos e inclusões exógenas [2].

No caso dos aços inoxidáveis, os aglomerados ou clusters de aluminatos, em especial do espinélio $\mathrm{MgO} \cdot \mathrm{Al}_{2} \mathrm{O}_{3}$, são considerados a principal fonte desse defeito pois, como possuem alta dureza e alto ponto de fusão, dificilmente sofrem deformação durante a laminação a quente [3].

Exemplos desse defeito em um aço AISI 430 e AISI 304 são mostrados na Figura 1 [1] e Figura 2 [2], respectivamente. Na Figura 1b [1] a análise microestrutural mostra que as inclusões aparentam ter origem em clusters, presentes originalmente na placa, antes da laminação [1].
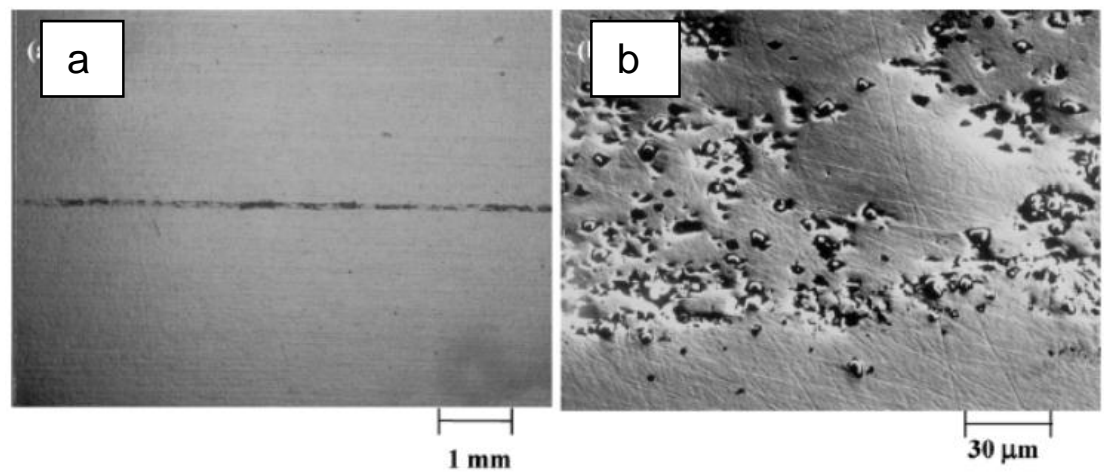

Figura 1. (a) e (b): imagens de microscópio eletrônico de varredura com diferentes aumentos de defeito de esfoliação encontrado na superfície de um aço 430 (0,58mm) [1].

* Contribuição técnica ao 450 Seminário de Aciaria - Internacional, 25 a 28 de maio de 2014, Porto Alegre, RS, Brasil. 

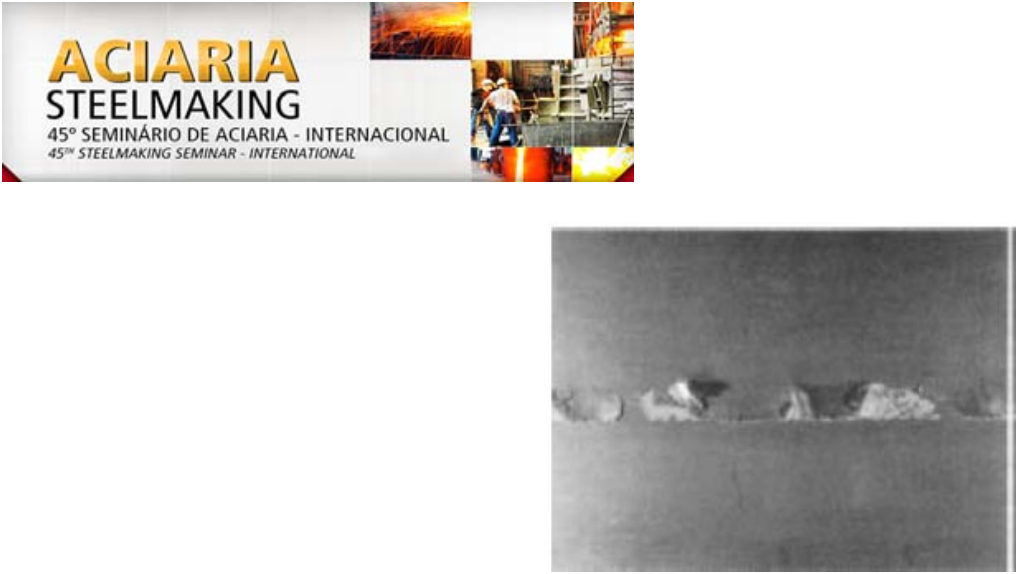

Figura 2. Defeito de esfoliação severo em aço 304 [2].

Com o intuito de diminuir a formação desse tipo de inclusão de aluminato, a desoxidação desses aços pode ser feita através da adição de silício. Entretanto, essa medida não é suficiente para eliminar a formação por completo desse tipo de aluminato, já que a forma $\mathrm{MgO} \cdot \mathrm{Al}_{2} \mathrm{O}_{3}$ apresenta estabilidade em uma grande faixa de temperaturas e composições químicas, bastando, como pode ser visto na Figura 3 [1] para um aço inoxidável austenítico, a presença de pequenas quantidades de magnésio, da ordem de 1 ppm, e de alumínio, da ordem de 60ppm, a $1550^{\circ} \mathrm{C}$ para sua formação.

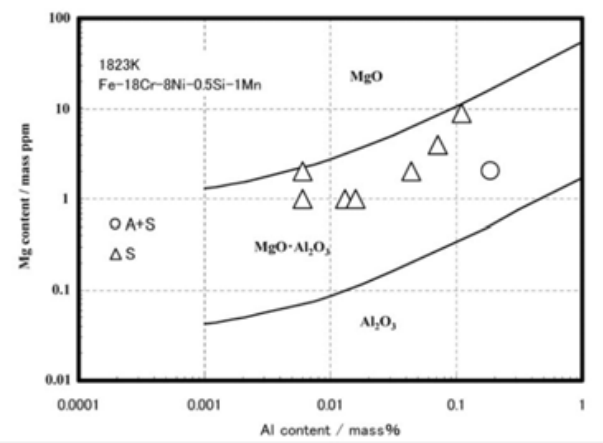

Figura 3. Diagrama de equilíbrio de fase da composição das inclusões baseada em resultados experimentais [1].

Outra possível alternativa para diminuição dos desvios de qualidade quanto ao acabamento superficial seria atuar nas fontes de magnésio existentes durante 0 processo de produção do aço líquido para controlar o teor desse elemento no banho e, como consequência, a formação do espinélio. Essa opção em termos práticos, entretanto, não é geralmente considerada, pois o controle do teor de magnésio abaixo de 1 ppm torna-se complexo e o uso de refratário a base de MgO é comprovadamente a opção mais eficiente para aços inoxidáveis devido à composição da escória utilizada para seu refino [1].

Um dos tratamentos empregados para mitigar os problemas superficiais trazidos pelo espinélio de alta dureza é o tratamento feito com cálcio. O cálcio reage com o espinélio de $\mathrm{MgO} \cdot \mathrm{Al}_{2} \mathrm{O}_{3}$ formando um alumino-silicato de ponto de fusão mais baixo, líquido à temperatura do banho, o que ajuda no controle desse tipo de defeito [1].

Entretanto, apesar do emprego da desoxidação por silício e do tratamento com cálcio, a formação desse tipo de espinélio continua a ser causa de defeitos superficiais em aços inoxidáveis de alta exigência quanto ao acabamento superficial. O presente trabalho mostra resultados positivos quanto à diminuição do defeito de esfoliação pela formação de espinélio em corridas industriais do aço 430 estabilizado ao nióbio na Aperam South America. A diminuição do índice de desvios de produção foi obtida através de melhores práticas de controle de processo e de desenvolvimento, junto ao fornecedor Companhia Brasileira de Metalurgia e

* Contribuição técnica ao $45^{\circ}$ Seminário de Aciaria - Internacional, 25 a 28 de maio de 2014, 
Mineração (CBMM), de uma liga de ferro-nióbio contendo menores teores de alumínio com relação ao produto padrão, o que será abordado nesse estudo.

\section{MATERIAL E MÉTODOS}

\subsection{Método de Produção do Aço 430E}

O processo de fabricação do aço inoxidável 430E é inciado com a fusão das matérias primas em fornos elétricos a arco (FEA) e com a produção do ferro-gusa nos alto-fornos. O ferro-gusa dos alto-fornos é desfosforado na estação de prétratamento de gusa (PTG) e em seguida misturado ao metal fundido nos fornos elétricos a arco. Este produto é então carregado no convertedor AOD-L, onde ocorre o processo de refino, sendo convertido em aço [4].

Em geral, duas rotas diferentes podem ser empregadas para o aço inoxidável: a rota Duplex e a rota Triplex. Na rota principal e de menor custo, a Duplex, o aço écompletamente descarburado no AOD-L e o ajuste final de composição química e temperatura são realizados na Metalurgia da Panela e Forno Panela, respectivamente. Na rota Triplex, o aço é parcialmente descarburado no convertedor AOD-L, a etapa final de descarburação é realizada num desgaseificador a vácuo (VOD) e o ajuste final da composição química e temperatura são realizados no Forno Panela [4]. A existência dessas duas rotas aumenta a flexibilidade na Aciaria e permite reduzir o custo de produção de algumas variedades de inox via rota Duplex. A Figura 4 mostra o fluxo de produção na rota Duplex e Triplex, para o aço 430E na Aperam.



Figura 4. Fluxograma simplificado de produção do aço inoxidável na Aciaria da Aperam [4].

\subsection{Método de Adição da Liga Ferro-Nióbio (FeNb)}

Para a produção das corridas do aço 430 com nióbio (430E), é utilizada a rota principal, Duplex. Nela, a liga ferro-nióbio (FeNb) a granel é adicionada ao aço líquido no AOD-L, após a completa desoxidação da corrida através da adição de ferro-silício (FeSi).

Vale ressaltar que, quando a produção ocorre via rota Triplex, o FeNb é adicionado sob vácuo no VOD. Portanto, em ambas as rotas, as adições de FeNb devem ocorrer após esta operação, quando o aço estiver completamente desoxidado com silício.

Corridas que apresentam teor de nióbio inferior ao necessário para garantir estabilização do aço após AOD-L, passam por ajustes de composição química na Metalurgia da Panela, mediante a adição de FeNb para acerto da composição. Estas adições ocorrem em corridas que apresentam rendimento de $\mathrm{Nb}$ menor do que o

* Contribuição técnica ao 450 Seminário de Aciaria - Internacional, 25 a 28 de maio de 2014, Porto Alegre, RS, Brasil. 
esperado no AOD-L. As razões para menores rendimentos na incorporação do nióbio ao aço no AOD-L são discutidas no item RESULTADOS E DISCUSSÃO.

\subsection{Caracterização da Esfoliação no Aço 430E}

Amostras do aço 430E que apresentaram o defeito "esfoliação" na bobina laminada a frio, foram caracterizadas através de um Microscópio Eletrônico de Varredura (MEV) com um analisador de imagens acoplado. A composição química dos elementos presentes na microestrutura foi analisada via EDS.

O índice de defeito nas bobinas do aço 430E, foi correlacionado com as o teor de alumínio nas corridas produzidas na Aciaria de acordo com a Equação 1.

ÍNDICE DE DESVIOS $(\%)=\quad 100 \times$ TONELADAS DESVIADAS

(TONELADAS INSPECIONADAS)

\subsection{Metodo de Produção do Ferro-Nióbio com Menor Teor de Alumínio}

A liga ferro-nióbio é fornecida contendo de $63 \%$ a $67 \%$ de $\mathrm{Nb}$ com diferentes especificações de composição química e de granulometria, para atender às mais diversas aplicações da indústria siderúrgica. $\mathrm{Na}$ Tabela 1 são apresentadas as especificações químicas do FeNb especificação 111 (standard) e do FeNb 117, com teor máximo de alumínio de 0,7\%,fornecidas pela empresa CBMM.

Tabela 1. Especificação de composição química do FeNb 111 e 117

\begin{tabular}{|c|c|c|c|c|c|c|c|c|}
\hline \multirow{2}{*}{ PRODUTO } & $\mathbf{N b}$ & $\mathbf{F e}$ & $\mathbf{A l}$ & $\mathbf{P}$ & $\mathbf{C}$ & $\mathbf{T a}$ & $\mathbf{N}$ & $\mathbf{S}$ \\
\cline { 2 - 6 } & \multicolumn{7}{|c|}{$\mathbf{( \% )}$} \\
\hline $\mathbf{1 1 1}$ & $63,5-67,5$ & Balanço & 2,0 máx. & 0,22 máx. & 0,20 máx. & 0,20 máx. & 0,10 máx. & 0,04 máx. \\
\hline $\mathbf{1 1 7}$ & $63,0-67,5$ & Balanço & 0,7 máx. & 0,22 máx. & 0,20 máx. & 0,20 máx. & 0,10 máx. & 0,04 máx. \\
\hline
\end{tabular}

De acordo com o fornecedor, o FeNb é produzido por redução aluminotérmica de concentrado de nióbio em forno de arco elétrico. O processo produtivo consiste nas seguintes etapas: a) pesagem e homogeneização da mistura de concentrado refinado de nióbio, alumínio e ferro em pó, b) alimentação da mistura e redução aluminotérmica em forno elétrico, c) vazamento e granulação da escória, d) vazamento e lingotamento do FeNb líquido e e) resfriamento e britagem dos lingotes de $\mathrm{FeNb}$, atendendo às diversas especificações de granulometria. O novo produto desenvolvido, especificação 117, apresenta menores teores de alumínio, obtido pelo desenvolvimento de um novo mix de material redutor e ajustes feitos no processamento em forno elétrico.

\subsection{Realização dos Testes Industriais}

A liga desenvolvida foi utilizada inicialmente somente para acertos de nióbio em adições nos processos posteriores ao AOD-L, na Metalurgia da Panela. Casos estes em que o rendimento atingido no processo de produção era menor que o esperado. As adições após desoxidação por FeSi no AOD-L continuaram a ser feitas com o FeNb 111.

A qualidade das corridas produzidas foi monitorada através do acompanhamento do índice de desvios por esfoliação no aço 430E.

* Contribuição técnica ao 45 Seminário de Aciaria - Internacional, 25 a 28 de maio de 2014, 


\section{RESULTADOS E DISCUSSÃO}

A caracterização do defeito nas bobinas laminadas a frio do aço 430E no MEV apresentaram elementos como $\mathrm{Mg}$, $\mathrm{Al}$ e $\mathrm{O}$ em alta concentração, sugerindo serem inclusões de aluminatos do tipo espinélioMgO. $\mathrm{Al}_{2} \mathrm{O}_{3}$, conforme observado por Park et al (2010) [1]. A Figura 5 a a5d mostram os resultados das análises realizadas.

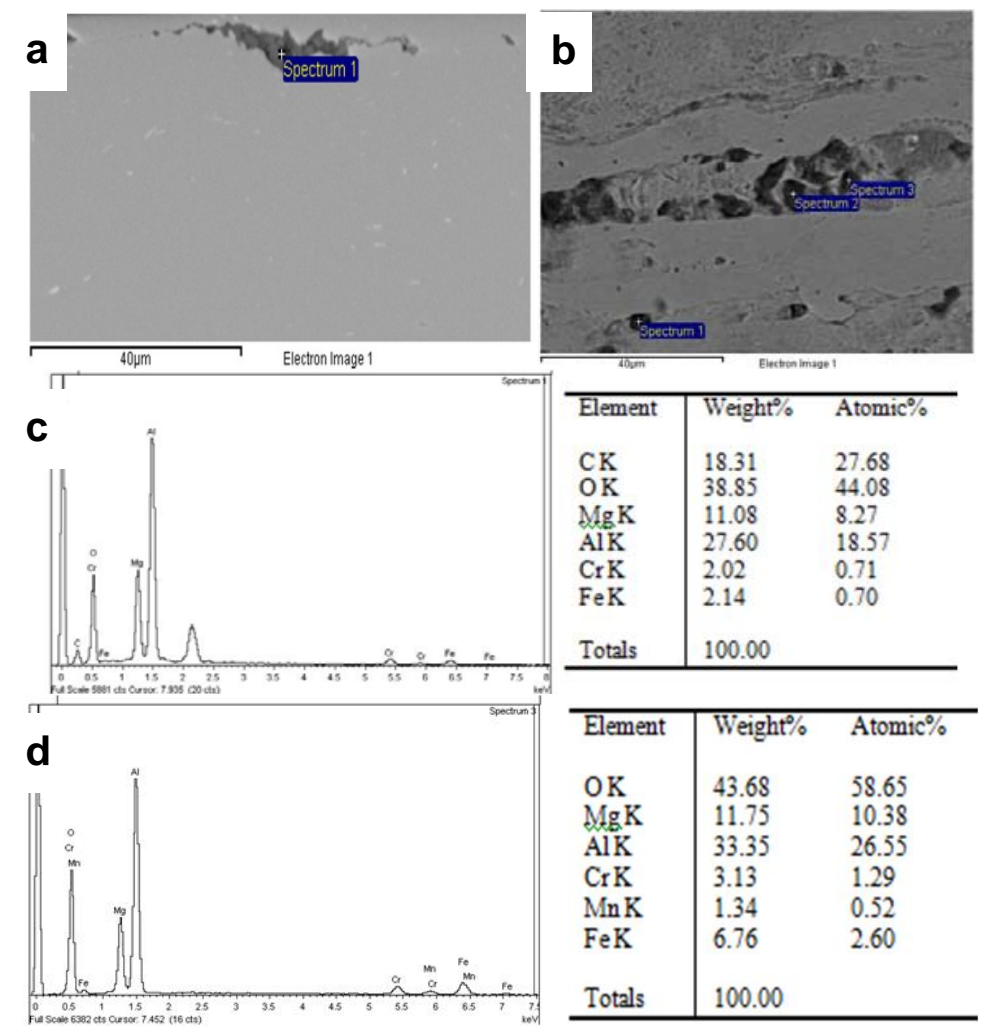

Figura 5. (a-b) Imagens do defeito de esfoliação no aço 430E observadas no MEV. (c) resultado da análise de EDS para esfoliação observada na figura $5 a$. (d) resultado da análise de EDS para esfoliação observada na figura 5b.

Os defeitos ocorreram em placas provenientes de corridas feitas na rota Duplex em que o rendimento da adição de FeNb 111 no AOD-L foi abaixo do esperado, havendo a necessidade de correção na Metalurgia da Panela. Na rota Duplex, o rendimento de FeNb é prejudicado em relação à rota Triplex. As principais perdas ocorrem basicamente pelos seguintes fatores: saída de partículas finas para atmosfera como poeira pelo sistema de exaustão do conversor, o aprisionamento de partículas na escória, impossibilitando o contato da liga com o aço líquido e a possibilidade do nióbio dissolvido reagir com o oxigênio do aço formando óxidos de $\mathrm{Nb}$, ocorrendo perda por oxidação [5]. Devido a estas perdas (pela atmosfera, escória ou pela oxidação), faz-se necessário acerto do teor de nióbio nos processos posteriores ao AOD- L na produção via rota Duplex. Quando o FeNb é adicionado na Metalurgia da Panela, ele leva consigo a incorporação de alumínio no aço que, como comentado anteriormente, para aços inoxidáveis, mesmo em pequenos teores torna possível a formação do espinélio $\mathrm{MgO} \cdot \mathrm{Al}_{2} \mathrm{O}_{3}$ [1]. Dependendo do grau deste tipo de inclusão, não há tempo suficiente para a total flotação e retirada via escória, ocasionando maior frequência de defeitos do tipo esfoliação. A Figura 6 mostra o efeito da incorporação de alumínio via adição de FeNb 111 na Metalurgia da Panela no índice de desvios por esfoliações no aço 430E. Para esse

* Contribuição técnica ao 45 Seminário de Aciaria - Internacional, 25 a 28 de maio de 2014, Porto Alegre, RS, Brasil. 


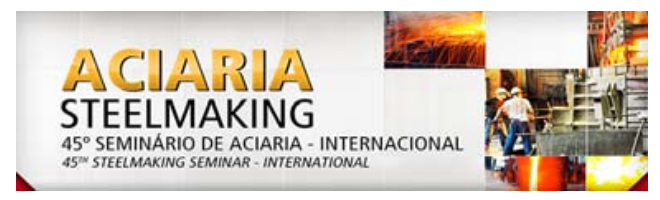

cálculo considerou-se um teor médio de alumínio no FeNb 111 de 1,33\% e incorporação de todo o alumínio presente na ferro-liga no banho. A relação mostrou que quanto maior a incorporação de alumínio nesta etapa, em corridas produzidas na rota Duplex, maior é o índice de desvios por qualidade devido à esfoliação. A condição mais crítica ocorre para incorporações de alumínio acima de um quilograma, ocasionando maior índice de desvios.

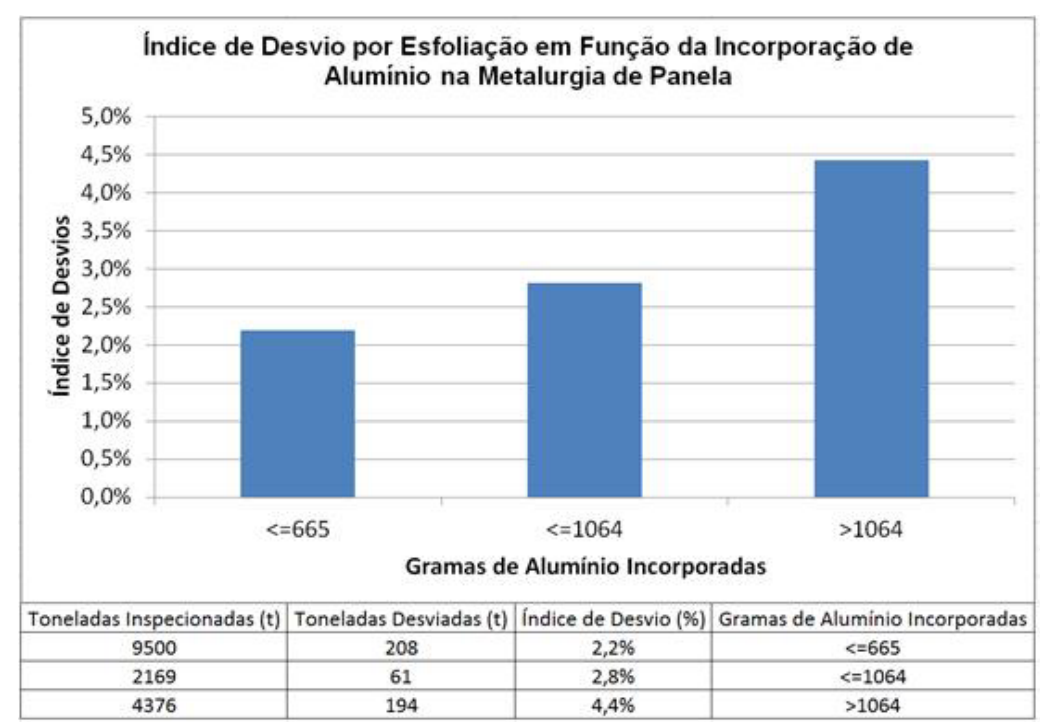

Figura 6. Efeito da quantidade de alumínio incorporada na panela após AOD-L no índice de desvios por esfoliação no aço 430E.

A Figura 7 mostra a evolução do índice de desvios por esfoliação no aço 430E. As primeiras corridas experimentais com a adição de FeNb 117 foram produzidas ainda em 2011, porém em escala reduzida. Em 2012, passou ser utilizada para teste em algumas corridas para correção de composição, especificamente em corridas com necessidades de adição após o AOD-L na Metalurgia da Panela. Embora o índice de utilização do FeNb 117 fosse baixo em relação ao total produzido, durante os acompanhamentos observou-se que as corridas produzidas apresentavam menor índice de desvio por esfoliação quando essa nova liga era adicionada. Em 2013 passou-se a utilizar a liga FeNb 117 em 100\% das adições no 430E, seja diretamente no vaso do AOD-L, como nas adições para acertos na Metalurgia da Panela ou no VOD (via rota Triplex). O teor de alumínio nas ligas de FeNb passou de um valor médio de 1,33\% em 2012 para 0,26\% em 2013. O gráfico abaixo mostra o principal resultado obtido com o desenvolvimento: a redução no índice de desvios por esfoliações no aço 430E.

* Contribuição técnica ao $45^{\circ}$ Seminário de Aciaria - Internacional, 25 a 28 de maio de 2014, 

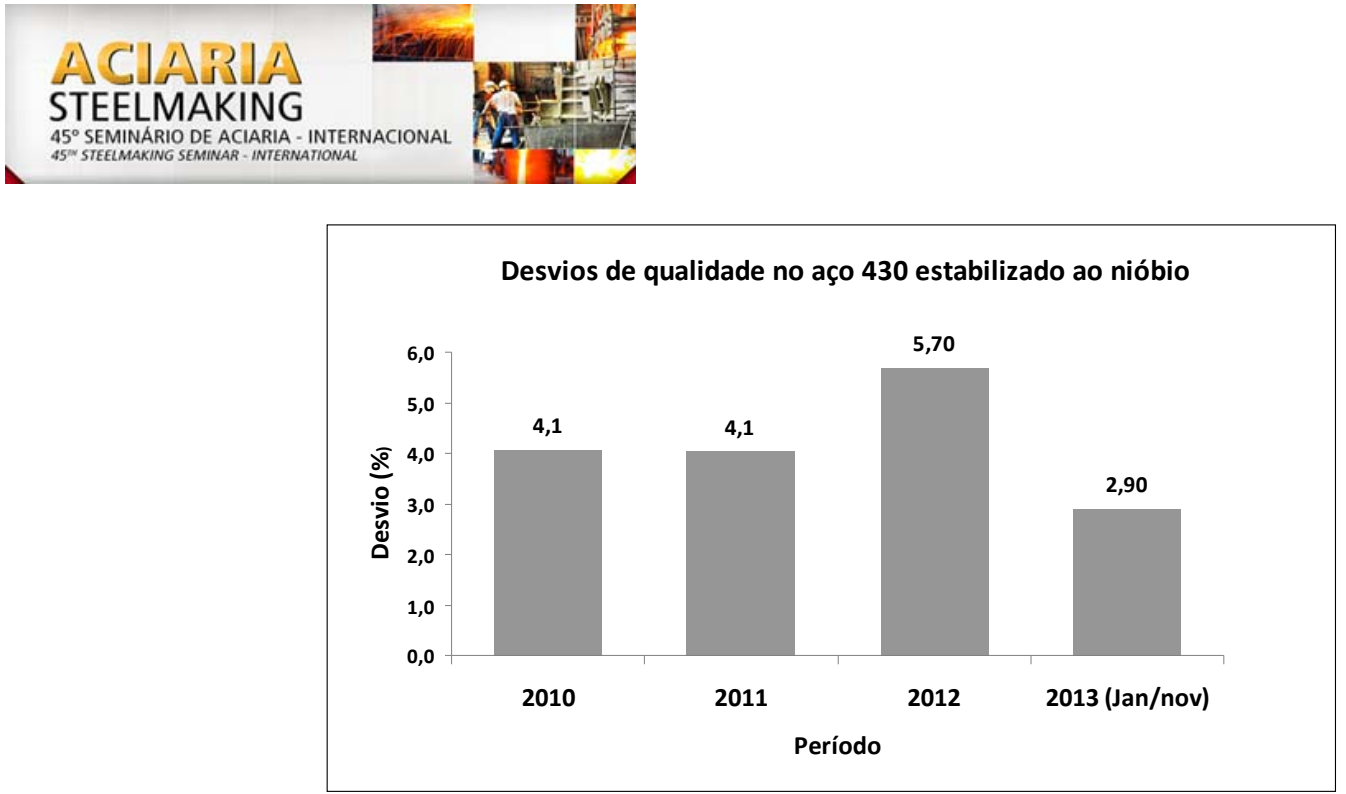

Figura 7. Evolução do índice de desvios por esfoliação no aço 430E.

Em 2012, devido a necessidade de adição de FeNb 111 na Metalurgia da Panela em uma quantidade maior de corridas, por questões de rendimento, houve um maior índice de desvios. No entanto, como pode ser observado no gráfico, em 2013, o índice de desvio por esfoliação no aço $430 \mathrm{E}$ foi reduzido para 2,9\%, quando foi implementada a utilização da liga FeNb 117 em 100\% das corridas, atingindo redução no índice de desvios de 29\% em relação aos níveis de 2010 e 2011.

\section{CONCLUSÃO}

O controle do teor de alumínio incorporado no aço 430E, acalmado ao silício e contendo 0,20 a 0,40\% de nióbio, obtido através do desenvolvimento e aplicação da liga FeNb 117, contendo menores teores de alumínio, e do rigoroso controle de processo, permitiu reduzir a formação de inclusões do tipo $\mathrm{MgO} \cdot \mathrm{Al}_{2} \mathrm{O}_{3}$ que, por apresentarem elevada dureza e alto ponto de fusão, são as principais fontes causadoras de defeito tipo esfoliação, originados na Aciaria em aços inoxidáveis. Com a diminuição dessas inclusões, o índice de desvios por esfoliação no aço 430E foi reduzido de 4,1\% em 2010 e 2011 para 2,9\% em 2013, ou seja, uma redução significativa nos desvios de $29 \%$, o que aumentou a flexibilidade da APERAM de alocação das bobinas produzidas para diversas aplicações.

\section{REFERÊNCIAS}

1 Park JH, Todoroki H. Control of $\mathrm{MgO} \cdot \mathrm{Al}_{2} \mathrm{O}_{3}$ Spinel Inclusions in Stainless Steels. ISIJ International. 2010;50(10):1333-46.

2 Zhang L, Thomas BG. State of the art in evaluation and control of steel cleanliness. ISIJ International. 2003;43(3):271-91.

3 Shufeng $\mathrm{Y}$, Jingshe L, Lifeng Z, Pealslee KE, Zaife W. Evolution of $\mathrm{Mgo} \cdot \mathrm{Al}_{2} \mathrm{O}_{3}$ based inclusions in alloy steel during the refining process. Metallurgicaland Mining Industry. 2010;2(2):87-92.

4 Filho DS, Marin H, Silva JMF, Porto R. Análise da redução do pick-up de nitrogênio na produção dos aços inoxidáveis. In: Anais do $42^{\circ}$ Seminário de Aciaria; 2011; Salvador, Brasil. São Paulo: ABM; 2011.

5 Kajioka H, Kozasu I, Hashimoto O, Abe M, Katsumata M, Sawaragi Y. Niobium, how to use niobium for improvement of steel properties. Tokyo: CBMM-Asia Company; 2005. p.128.

* Contribuição técnica ao $45^{\circ}$ Seminário de Aciaria - Internacional, 25 a 28 de maio de 2014, Porto Alegre, RS, Brasil. 